\title{
location and dimension of mandibular canal on cone beam computed tomography: A cross sectional study
}

\author{
Farzaneh Mirhoseini $^{1}$, Motahare Baghestani ${ }^{2}$, Mohammad Hadi Khajezade ${ }^{3}$, Ali Derafshi ${ }^{2}$, \\ Motahareh Kaboodsaz yazdi
}

\begin{abstract}
1 Department of Oral and Maxillofacial Radiology, Faculty of Dentistry, Shahid Sadoughi University of Medical Sciences, Yazd, Iran.

2. Department of Oral and Maxillofacial Radiology, Faculty of Dentistry, Shahid Sadoughi University, Yazd, Iran.

3. Dentist, Yazd, Iran.
\end{abstract}

\section{Article Type:}

Original Article

\section{Article History:}

Received: 28 Feb 2019

Revised: 6 Oct 2019

Accepted: 7 Jul 2019

\section{*Correspondence:}

Motahare Baghestani, Department of Oral and Maxillofacial Radiology, Faculty of Dentistry, Shahid Sadoughi University, Yazd, Iran. baghestani.motahare@yah oo.com

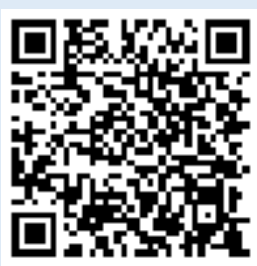

\begin{abstract}
Background and objective: Accurate understanding of the anatomy of the inferior alveolar nerve (IAN) and its relation with anatomical landmarks of mandibular molar teeth can reduce the risk of unwanted injuries to the IAN during implant placement.
\end{abstract}

Methods: 44 CBCTs of patients, who have been reffered to the private oral and maxillofacial radiology center, were examined by a radiologist on the axial, sagittal and coronal planes. Then, the distances between mandibular canal and buccal cortex (BN) and lingual cortex (LN), buccolingual width of the mandibular canal (BL), and the distances between the canal and apex of the first molar (M1N) and second molar of mandible (M2N) were obtained from cross-sectional images. Data were analyzed using SPSS17 software and Kolmogorov-smirnov and Mann-whitney test.

Results: 21 males and 23 females aged 20 to 50 years old (mean age: $37.8 \pm 7.52$ ) were examined. The mean intervals in the regions of first molar in the right and left sides were BN: 4.03,4.06 mm, LN: 2.10,2.58 mm, BL: 2.20,2.20 mm, and M1N: 5.77,5.78 mm and in the second molar region, on the right and left sides were $\mathrm{BN}: 5.21,5.20 \mathrm{~mm}, \mathrm{LN}$ : 1.95,1.80 $\mathrm{mm}$ and BL: $2.30,2.20 \mathrm{~mm}$ and M2N: $3.85,3.55 \mathrm{~mm}$, respectively. There was a significant difference in the mean buccolingual width of mandibular canal in both sides in the region of first molar and left side in the region of second molar between two genders. $(\mathrm{P}=0.009, \mathrm{P}=0.019, \mathrm{P}=0.045)$. Other measurements were not significantly different between two genders $(\mathrm{P}>0.05)$. The age range of patients had no effect on any of the distances and measurements $(\mathrm{P}>0.05)$.

Conclusion: buccolingual width of mandibular canal in both sides in the region of first molar and left side in the region of second molar was associated with gender.

Keywords: Locatin, dimensions, inferior alveolar canal, mandibular canal, CBCT

Copyright $@$ 2018, Jorjani Biomedicine Journal has published this work as an open access article under the terms of the Creative Commons Attribution License (http://creativecommons.org/licenses/by-nc/4.0/) which permits noncommercial uses of the work while it is properly cited. 


\section{Introduction}

Inferior alveolar canals (IAC) are anatomical structures that extend bilaterally from the mandibular foramen to the mental foramen. These canals include the inferior alveolar nerve and vessels that extend horizontally along the mandibular bone(1). There are Significant variations in the shape, type of curvature, and pathway of the inferior alveolar nerve that precludes accurate prediction of the location of the inferior alveolar nerve during various surgeries (such as third molar surgery, implant placement, osteotomy or fracture repair surgery), and causes multiple problems, such as iatrogenic damage to the inferior alveolar nerve(2). Overall damage to the inferior alveolar nerve during surgical procedures performed have been reported in $13.2 \%$ (3). Considering anatomical landmarks related to mandibular canal, can reduce the risk of undesirable damage to the inferior alveolar nerve during various surgeries in this area(1). However panoramic is a regular imaging, but its disadvantages are being two-dimensional imaging and improper sharpness(4). While in CBCT the dose of radiation is reduced to a considerable extent(in compared with computer tomography) and also provides an isotrophic resolution and high dimentional accuracy(5). Several studies have been done to examine the position of the IAC. Hidehito et al. concluded that the location of the IAC was correlated with age, gender and region(6). Adigüzel et al. concluded that the distance between the inferior alveolar nerve and the root of the mandibular molar first molars in female in all age groups was lower than male. This gap is shorter in the distal root of each of the two genders than the mesial root. In addition, the two genera are less than the other age groups in the very young and very old age groups(7). Sheng L et al observed that the lingual cortex of the mandibular canal was thinner than the buccal cortex, and the distance between the mandibular canal and the buccal cortex gradually increased from proximal to distal, although the distance between the mandibular canal and the lingual cortex and alveolar crest gradually decreased from proximal to distal. There was no significant difference between the height, width, and thickness of cross sections of mandibular body cortex on the left and right sides. Males have thicker mandibles than female. (8). Yashar et al. observed significant differences between the two genders in assessing the amount of bone surrounding the mandibular canal(9). Considering the precision of CBCT and its importance in evaluating the position of the IAC in implant placement and various surgeries in this area, in this study, the intrabony position of the mandibular canal in the first and second molars of the dentulous patients was investigated according to CBCT images.

\section{Materials and Methods}

The research has employed a cross-sectional method. After obtaining the approval of the Ethics Committee of the Yazd University of Medical Sciences, R.SSU.REC.1395.173, 44 CBCT stereotypes derived from individuals referring to an oral and maxillofacial radiology clinic in Yazd, in 2014-16 for various reasons such as implant placement, etc. through easy method. Then, the required data were extracted and collected through observing the data. CBCT scans were prepared by the PROMAX 3D device (Planmeca; Helsinki, Finland) with a size 160 $\mathrm{mm}$, and exposure parameters of $12 \mathrm{~mA}$ and $84 \mathrm{kvp}$, and an exposure time of 13 seconds, and the field of view of $0.08 \times 8.8 \mathrm{~mm}$. The 
data was imported in to the software after the collection and stored in DICOM format on $\mathrm{CD}$ and placed in a viewer's direction.

The inclusion criteria for the study were the following cases:

1. Having all 14 mandibular teeth (except for third molar teeth)

2. Lack any pathologies or developmental disorders or any previous treatments that may affect the position of the inferior alveolar nerve.

\section{High resolution images}

4. Images that contain information about the age and gender of the patients.

Evaluation of the images were done by an oral and maxillofacial radiologist using the Planmeca Romexis Viewer 2.9.2.R program in axial, sagittal and coronal planes at desired conditions in terms of brightness and contrast in a semi-dark room on a laptop monitor screen 15, 6-inch HD resolution and 4GB RAM in same conditions, and the information was recorded in pre-made forms. The secondary reconstruction of the images was done in Planmeca Romexis Viewer 2.9.2.R. The position and dimensions of the mandibular canal were measured using the measure-length tool in the planmeca Romexis Viewer 2.9.2.R program and measured on cross-sectional sections as:

- The distance between the buccal mandibular cortex and the buccal cortex of the mandibular canal in the first and second molars regions (BN1, BN2).

- The distance between the lingual mandibular cortex and lingual cortex of the IAC in the first and second molars regions (LN1, LN2).

- The distance between superior cortex of the IAC and the apex of the mesial root of the first and second molars of the mandible (M1N, M2N)
- Buccolingual width of IAC in the first and second molar regions (BL1, BL2) (Figure1)

In addition, the data such as gender (male, female), age (by year) and side of each patient were recorded. Tables and indicators were completed using descriptive statistics and SPSS17 software. Based on Kolmogorovsmirnov $\mathrm{P}$-values of $\mathrm{BN} 1, \mathrm{BN} 2$ and $\mathrm{M} 1 \mathrm{~N}$ are more than 0.05 that have normal distribution and avarage values are expressed for them.For other values Mann-whitney test have conducted and mean values are expressed for them.

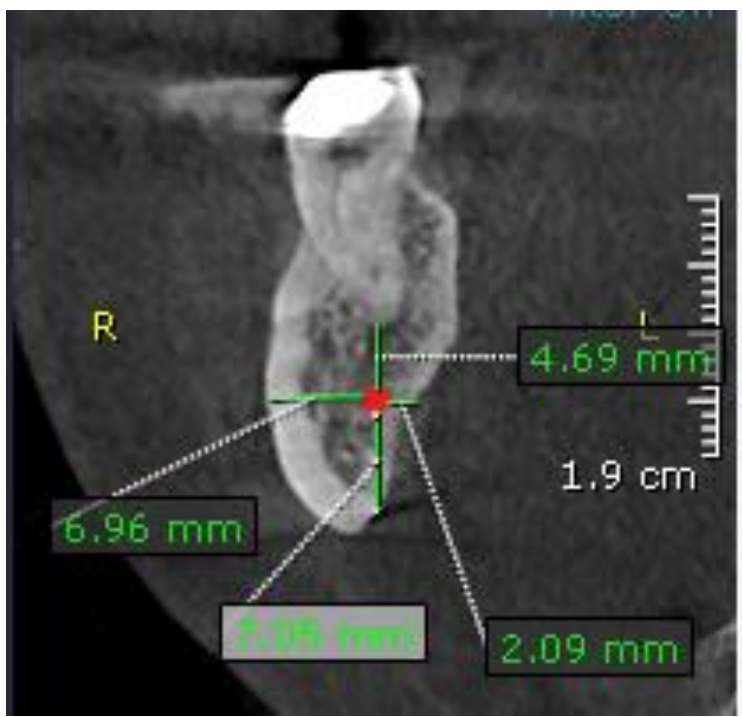

Figure 1: Parameters of the inferior alveolar nerve canal measured in this study

\section{Results}

In this study, 21 males and 23 females were examined. The mean intervals in the first molar in the left and right sides wereBN: 4.03,4.06 mm, LN: 2.10,2.58 mm, BL: 2.20,2.20 mm, and M1N: 5.77,5.78 $\mathrm{mm}$ and in the second molar region, on the right and left sides were $\mathrm{BN}$ : 5.21,5.20 $\mathrm{mm}, \mathrm{LN}$ : 1.95,1.80 $\mathrm{mm}$ and BL: 2.30,2.20 $\mathrm{mm}$ and M2N: 3.85,3.55 mm, respectively.

The mean intervals on the right side in female and male were $\mathrm{BN}: 3.73,4.36 \mathrm{~mm}$ and $\mathrm{LN} 1$ : 
2.10,2.20 mm BN2: 5.21,5.19 $\mathrm{mm}$ and LN2: $1.90,2.00 \mathrm{~mm}$, respectively. In addition, the mean intervals on the left side in female and male were BN1: $3.79,4.36 \mathrm{~mm}$ and $\mathrm{LN} 1$ : 2.62,2.30 $\mathrm{mm}$ BN2: $5.06,5.36 \mathrm{~mm}$ and LN2:2.10,1.70 mm, respectively. Based on Ttest, there was not any significant differences in the mean distances of mandibular canal to the buccal and lingual cortex of mandible in the two genders. (Table 1).

Buccolingual width of canal on the right side in female and male were BL1: 2.20,2.10 mm
B12:2.30,2.20 mm, respectively. These values for the left side were BL1: $2.40,2.20 \mathrm{~mm}$ and BL2: $2.45,2.20 \mathrm{~mm}$, respectively. There was a significant difference in the mean buccolingual width of mandibular canal in both sides in the region of first molar and left side in the region of second molar between two genders. $(\mathrm{P}=0.009, \mathrm{P}=0.019, \mathrm{P}=0.045)$. Other measurements were not significantly different between two genders $(\mathrm{P}>0.05$ (Table $1)$.

Table 1: The mean intervals in two genders(female and male)

\begin{tabular}{|c|c|c|c|c|c|c|c|}
\hline \multirow[t]{2}{*}{ Intervals } & \multirow[t]{2}{*}{ Side } & \multicolumn{2}{|c|}{ Female } & \multicolumn{2}{|c|}{ Male } & \multirow[t]{2}{*}{ P value } & \multirow[t]{2}{*}{ Total mean } \\
\hline & & number & distance & number & distance & & \\
\hline \multirow[t]{2}{*}{$\mathrm{BN} 1^{*}$} & Right side & 23 & 3.73 & 21 & 4.36 & 0.20 & 4.03 \\
\hline & Left side & 23 & 3.79 & 21 & 4.36 & 0.20 & 4.06 \\
\hline \multirow[t]{2}{*}{ LN1 } & Right side & 23 & 2.10 & 21 & 2.20 & 0.69 & 2.10 \\
\hline & Left side & 23 & 2.62 & 21 & 2.30 & 0.12 & 2.58 \\
\hline \multirow[t]{2}{*}{$\mathrm{BN} 2 *$} & Right side & 23 & 5.21 & 21 & 5.19 & 0.054 & 5.21 \\
\hline & Left side & 23 & 5.06 & 21 & 5.36 & 0.20 & 5.20 \\
\hline \multirow[t]{2}{*}{ LN2 } & Right & 23 & 1.90 & 21 & 2.00 & 0.62 & 1.95 \\
\hline & Left & 23 & 2.10 & 21 & 1.70 & 0.238 & 1.80 \\
\hline \multirow[t]{2}{*}{ BL1 } & Right & 23 & 2.20 & 21 & 2.10 & 0.009 & 2.20 \\
\hline & Left & 23 & 2.40 & 21 & 2.20 & 0.019 & 2.20 \\
\hline \multirow[t]{2}{*}{ BL2 } & Right & 23 & 2.30 & 21 & 2.20 & 0.57 & 2.30 \\
\hline & Left & 23 & 2.45 & 21 & 2.20 & 0.045 & 2.20 \\
\hline \multirow[t]{2}{*}{ M1N* } & Right & 23 & 5.15 & 21 & 6.4 & 0.20 & 5.77 \\
\hline & Left & 23 & 5.30 & 21 & 6.29 & 0.07 & 5.78 \\
\hline \multirow[t]{2}{*}{$\mathrm{M} 2 \mathrm{~N}$} & Right & 23 & 3.50 & 21 & 4.50 & 0.23 & 3.85 \\
\hline & Left & 23 & 3.56 & 21 & 3.80 & 0.176 & 3.55 \\
\hline
\end{tabular}

\footnotetext{
Average values are expressed for these intervals and For others, mean values are expressed in the tables.
} 
The distance between the superior cortex of IAC and the apex of the mesial root of the first and second molars on the right side in female and male were 5.15,6.4 mm M1N: and $\mathrm{M} 2 \mathrm{~N}$ : $3.50,4.50 \mathrm{~mm}$, respectively. These values for the left side were M1N: 5.30.6.29 $\mathrm{mm}, \mathrm{M} 2 \mathrm{~N}: 3.56,3.80 \mathrm{~mm}$, respectively. The distance between IAC and apex of mesial root of mandibular first and second molars between two genders did not show any significant differences ( $\mathrm{P}>0.05$ ) (Table 2). All measurements were independently measured in two age groups under 40 and over 40 years old. On the right side, the measurements were performed in groups under 40 and above 40 , respectively: BN1: 4.04.4.02 $\mathrm{mm}$ and LN1: $2.55,2.10 \mathrm{~mm}$ and BN2: $5.08,5.35 \mathrm{~mm}$ and LN2: 2.05.1.55 mm and BL1: $2.25,2.20 \mathrm{~mm}$ and BL2: $2.45,2.20$ $\mathrm{mm}$ and M1N: 4.25, $5.98 \mathrm{~mm}$ and on the left side BN1: 4.02.4.12 $\mathrm{mm}$ and $\mathrm{LN} 1: 2.50,2.10$ $\mathrm{mm}$ and BN2: $5.03,5.41 \mathrm{~mm}$ and $\mathrm{LN} 2: 1.95$, $1.65 \mathrm{~mm}$ and BL1: $2.20,2.20 \mathrm{~mm}$ and BL2: $2.45,2.20 \mathrm{~mm}$ and $\mathrm{M} 2 \mathrm{~N}: 3.85,3.30 \mathrm{~mm}$, were obtained (Tables 2). In this study, the age range of patients (over 40 years old and under 40 years old) had no effect on any of the distances and measurements $(\mathrm{P}>0.05)$.

Table 2: The mean intervals in two age groups (under 40 and over 40 years old)

\begin{tabular}{|c|c|c|c|c|c|c|c|}
\hline \multirow[t]{2}{*}{ Interval } & \multirow[t]{2}{*}{ Side } & \multicolumn{2}{|c|}{ Under 40 years old } & \multicolumn{2}{|c|}{ over 40 years old } & \multirow[t]{2}{*}{$P$ value } & \multirow[t]{2}{*}{ Total mean } \\
\hline & & number & distance & number & distance & & \\
\hline \multirow[t]{2}{*}{ "BN1 } & Right & 24 & 4.04 & 20 & 4.02 & 0.94 & 4.03 \\
\hline & Left & 24 & 4.02 & 20 & 4.12 & 0.75 & 4.07 \\
\hline \multirow[t]{2}{*}{ LN1 } & Right & 24 & 2.55 & 20 & 2.10 & 0.83 & 2.10 \\
\hline & Left & 24 & 2.50 & 20 & 2.10 & 0.095 & 2.30 \\
\hline \multirow[t]{2}{*}{ *BN2 } & Right & 24 & 5.08 & 20 & 5.35 & 0.30 & 5.21 \\
\hline & Left & 24 & 5.03 & 20 & 5.41 & 0.08 & 5.22 \\
\hline \multirow[t]{2}{*}{ LN2 } & Right & 24 & 2.05 & 20 & 1.55 & 0.38 & 1.95 \\
\hline & Left & 24 & 1.95 & 20 & 1.65 & 0.09 & 1.80 \\
\hline \multirow[t]{2}{*}{ BL1 } & Right & 24 & 2.25 & 20 & 2.20 & 0.31 & 2.20 \\
\hline & Left & 24 & 2.20 & 20 & 2.20 & 0.54 & 2.20 \\
\hline \multirow[t]{2}{*}{ BL2 } & Right & 24 & 2.45 & 20 & 2.20 & 0.20 & 2.30 \\
\hline & left & 24 & 2.20 & 20 & 2.25 & 0.09 & 2.20 \\
\hline \multirow[t]{2}{*}{ "M1N } & Right & 24 & 4.25 & 20 & 5.98 & 0.59 & 5.78 \\
\hline & Left & 24 & 5.47 & 20 & 6.13 & 0.40 & 5.80 \\
\hline \multirow[t]{2}{*}{$\mathrm{M} 2 \mathrm{~N}$} & Right & 24 & 4.95 & 20 & 3.40 & 0.40 & 3.85 \\
\hline & Left & 24 & 3.85 & 20 & 3.30 & 0.71 & 3.55 \\
\hline
\end{tabular}

* Average values are expressed for these intervals and For others, mean values are expressed in the tables. 


\section{Discussion}

In the present research, 88 inferior alveolar canals were considered in terms of the canal borders distances to buccal and lingual mandibular cortex as well as the buccolingual width of the IAC and its distance to the apex of the teeth in the first and second molars of mandible in cross sections of the CBCT image from 44 patients were investigated.

Kim et al. divided the position of the IAC into 3 types. In type one, $70 \%$ of the canal is located along the lingual cortical cortex in the ramus and body of mandible. In the second type, $15 \%$ of the canal is at the back of the first and second molar in the middle of the ramus, and when it passes through the first and second molars regions, it lies along the lingual plate. In the third type, $15 \%$ of the canals extends in the middle or in one third of mandibular lingual from the ramus to the body of mandible, which is consistent with the results of this study(10).

Adiguzel et al. investigated the CBCT images of 200 patients (100 males and 100 females) in Turkey to study BN, LN and also M1N. They also assessed the effect of age and gender on these measurements. In their study, the $\mathrm{BN}$ and $\mathrm{LN}$ in male was $5.3 \pm 1.5$ and $2.7 \pm 1.8$, and $5.1 \pm 1.4$ and $2.6 \pm 1.7 \mathrm{~mm}$ in female. These sizes are similar to those obtained in the present study, and the difference in some values can be attributed to the racial difference and the difference in the number of samples. M1N in male and female was $5.1 \pm 1.6$ and $4.4 \pm 1.3 \mathrm{~mm}$, which was significantly higher in male than female(7), but there was no significant difference regarding this distance in both genders. Also, the distance between the IAC and the distal and mesial apexes of the first molar in the age groups of 16-25 and 56-65 years was lower than the other age groups (35-45,55-26,3646), $(\mathrm{P}<0.05)$. However, in the present study, there was no significant difference between the two age groups (under 40 and over 40 years old) in any of the measurements. Nair et al. (2013) surveyed 44 CBCT images in the United States. They reported $\mathrm{BN}$ and $\mathrm{LN}$ in the mesial root of the first molar in the right side as much as 5.1 and $2.5 \mathrm{~mm}$, respectively. The values for the left side were 4.8 and $2.7 \mathrm{~mm}$, respectively. The values of the mesial roots of the second molar in the right side were 6.2 and $2 \mathrm{~mm}$, and 5.7 and $2 \mathrm{~mm}$ for the left side. $\mathrm{M} 1 \mathrm{~N}$ and $\mathrm{M} 2 \mathrm{~N}$ in the right side were 4.8 and $2.8 \mathrm{~mm}$, and 4.8 and $3.4 \mathrm{~mm}$ for the left side(11). In the present study, BN and $\mathrm{LN}$ in the mesial root of the first molar in the right side as much as 4.03 and $2.10 \mathrm{~mm}$, and 4.06 and $2.58 \mathrm{~mm}$ for the left side. The distance in the mesial root of the second molar in the right side was 5.21 and $1.95 \mathrm{~mm}$, and 5.20 and $1.80 \mathrm{~mm}$, for the left side, which was similar to the study of Nair et al. The few differences that exist can be attributed to the difference in the races under study. M1N and M2N on the right side were 5.77 and $3.85 \mathrm{~mm}$, and 5.78 and $3.55 \mathrm{~mm}$ for the left side. These numbers are relatively higher in comparison with the results obtained in the Nair study, which can be attributed to racial differences. Kawashima et al. (2016) examined 155 CBCT images from patients aged 20 years old and over (68 males and 87 females) in the United States. BN and LN in the mesial root of the second molar in male and female were reported as much as 5.73 \pm 1.62 and $2.18 \pm 1.21$, and $6.03 \pm 1.41 \mathrm{~mm}$ and $2.73 \pm 1.13 \mathrm{~mm}$, respectively, which are relatively similar in comparison with the results of the present study (male, 5.19 and $2 \mathrm{~mm}$, female, 5.21 and $1.90 \mathrm{~mm}$ ). The reason for the slight difference in the measurements of the two studies can be attributed to the 
difference in studied races in the sample size. Kawashima et al. also concluded that the apex distance of the distal root of the second molar to the IAC in the left and right sides in male was significantly higher than female. In addition, LN on the left side in male is lower than female(12). However, in the present study, there was no significant difference in the distance between M1N and M2N between the two genders. In addition, $\mathrm{LN}$ in the first and second molars was not significant in male and female. Koivisto et al. reported that the IAC position was $57 \%$ buccal, $40 \%$ lower, and $3 \%$ lingual compared to the root of mandibular second molar, was $18 \%$ buccal, $55 \%$ lower, and $11 \%$ lingual compared to the root of mandibular first molar. In this study, the buccal bone thickness to the IAC had the highest rate $(5.30 \mathrm{~mm})$ in the mesial root of the second molar and the lowest rate $(2.60 \mathrm{~mm})$ in the second premolar. In general, by moving the IAC from the mesial root of the second molar to the anterior, the buccal bone thickness decreases compared to the IAC and increases the thickness of the lingual bone(13). In the present study, $\mathrm{BN}$ at the second molar are more than the values obtained in the first molar region. Balaji et al. (2012) conducted a pilot study on 10 CBCT images of 10 males and 10 females. The mean buccolingual width of the canal was reported in the first and second molars of the mandible as much as $25 \pm 35.2 \mathrm{~mm}$ and $30 \pm 43.2 \mathrm{~mm}$ (14), which is similar to the reported values in this study. In this study, M1N and M2N was $5.79 \mathrm{~mm}$ and $5.95 \mathrm{~mm}$ in the right side and $6.75 \mathrm{~mm}$ and $5.83 \mathrm{~mm}$ in the left side. These distances in the present study were $5.77 \mathrm{~mm}$ and $3.85 \mathrm{~mm}$ for the right side and $5.78 \mathrm{~mm}$ and $3.55 \mathrm{~mm}$ for the left side. There is a more difference between the two studies in the left side, which is due to the small sample size in Balaji et al. Study, and the differences in the studied races are justifiable. It should be noted that Balaji et al. examined the effect of gender on the studied variables. They observed that the thickness of the buccal and lingual cortex was significantly different between the two genders. This difference is effective on buccal and lingual cortex distances to the IAC. In the present study, there was a significant difference in BL1 of both sides and BL2 in the left side, and there was no significant difference between the two genders at LN. By comparing the results of two studies, it can be concluded that the observed difference between the two genders in values can be due only to the difference in the thickness of the buccal cortex between the two genders. Yashar et al. (2011) (9) showed a significant difference in $\mathrm{BN}$ values, but in this study there was no significant differences in BN between two genders, which can be attributed to racial differences.

\section{Conclusion}

buccolingual width of mandibular canal in both sides in the region of first molar and left side in the region of second molar was associated with gender.

It is recommended to emphasize on the importance of using CBCT in decreasing the risk of iatrogenic damage to the inferior alveolar nerve for implant-based therapies in retraining programs of dentists. In addition, similar studies with higher sample sizes are recommended in the future.

\section{Conflict of interest}

The authors declare that they have no competing interests.

\section{Authors' contributions}

All authors contributed equally to this work. 


\section{Highlights}

1) The current knowledge: The determination of the position and functions of IAC on CBCT images is effective in reducing the risk of iatrogenic damage to the IAN during surgeries.

2) What is new here: The determination of the position and functions of IAC on CBCT images in specific regions.

\section{References}

1. Razavi S.H BS, Sarikhani khorami Kh, Kaboodsaz yazdi M, Namiranian. The evaluation of mandibular canal visibility on cone beam computed tomography (CBCT) images: A crosssectional study. Jorjani Biomed J. 2019;7(3):5667.

2. Dos Santos Oliveira R, Maria Gomes Oliveira A, Cintra Junqueira JL, Kühl Panzarella F. Association between the Anatomy of the Mandibular Canal and Facial Types: A ConeBeam Computed Tomography Analysis. Int J Dent. 2018;2018:5481383-.

\section{[DOI:10.1155/2018/5481383]}

3. Wang D, Lin T, Wang Y, Sun C, Yang L, Jiang $\mathrm{H}$, et al. Radiographic features of anatomic relationship between impacted third molar and inferior alveolar canal on coronal CBCT images: risk factors for nerve injury after tooth extraction. Arch Med Sci. 2018;14(3):532-40. [DOI:10.5114/aoms.2016.58842]

4. Barzanji H, \& Tahir, A. Evaluation of the risk of inferior alveolar nerve injury during an implant procedure: A comparative study between OPG and CBCT. Erbil Dental Journal (EDJ). 2019;2(1):141-8. [DOI:10.15218/EDJ.2019.03]

5. Patel P, Shah J, Dudhia B, Butala P, Jani Y, Macwan R. Comparison of panoramic radiograph and cone beam computed tomography findings for impacted mandibular third molar root and inferior alveolar nerve canal relation. Indian Journal of
Dental Research. 2020;31(1):91-102. [DOI:10.4103/ijdr.IJDR_540_18]

6. Ogawa H, Kawashima Y. Location and Size of Mandibular Canal and Cortical Bone Width in the Second Molar Region. International Journal of Oral-Medical Sciences. 2019;17(3-4):53-61. [DOI:10.5466/ijoms.17.53]

7. Adiguzel O, Yigit-Ozer S, Kaya S, Akkus Z. Patient-specific factors in the proximity of the inferior alveolar nerve to the tooth apex. Medicina oral, patologia oral y cirugia bucal. 2012;17(6):e1103-8.

\section{[DOI:10.4317/medoral.18190]}

8. Sheng L, Qu W, Li Y, Qu Z, Wang J. [Threedimensional survey of the whole mandibular canal and mandibular morphology by cone beam computed tomography in normal young people]. Hua xi kou qiang yi xue za zhi = Huaxi kouqiang yixue zazhi $=$ West China journal of stomatology. 2016;34(2):156-61.

9. Yashar N, Engeland CG, Rosenfeld AL, Walsh TP, Califano JV. Radiographic considerations for the regional anatomy in the posterior mandible. Journal of periodontology. 2012;83(1):36-42. [DOI:10.1902/jop.2011.110076]

10. Kim ST, Hu KS, Song WC, Kang MK, Park HD, Kim HJ. Location of the mandibular canal and the topography of its neurovascular structures. J Craniofac Surg. 2009;20(3):936-9. [DOI:10.1097/SCS.0b013e3181a14c79]

11. Nair UP, Yazdi MH, Nayar GM, Parry H, Katkar RA, Nair MK. Configuration of the inferior alveolar canal as detected by cone beam computed tomography. J Conserv Dent. 2013;16(6):518-21. [DOI: 10.4103/09720707.120964]

12. Kawashima Y, Sakai O, Shosho D, Kaneda T, Gohel A. Proximity of the Mandibular Canal to Teeth and Cortical Bone. Journal of endodontics. 2016;42(2):221-4. [DOI:10.1016/j.joen.2015.11.009] 
13. Koivisto T, Chiona D, Milroy LL, McClanahan SB, Ahmad M, Bowles WR. Mandibular Canal Location: Cone-beam Computed Tomography Examination. Journal of endodontics. 2016;42(7):1018-21.

[DOI:10.1016/j.joen.2016.03.004]

14. Balaji SM, Krishnaswamy NR, Kumar SM,

Rooban T. Inferior alveolar nerve canal position

\section{How to cite:}

Mirhoseini F, Baghestani M, Khajezade M.H, Derafshi A, Kaboodsaz yazdi M. location and dimension of mandibular canal on cone beam computed tomography: A cross sectional study. Jorjani Biomedicine Journal. 2019; 7(4): 39-47. 